\title{
Interactive comment on "Determination of vadose and saturated-zone nitrate lag times using long-term groundwater monitoring data and statistical machine learning" by Martin J. Wells et
} al.

\author{
Martin Wells \\ mwells1992@gmail.com \\ Received and published: 24 July 2020
}

Dear Reviewers,

Once again, in order to maintain clarity and organization, our responses have been uploaded to the supplement document, linked below.

The document contains our response to Reviewers 1, 2, and 3. Please note, our response to Reviewers 1 and 2 have remained unchanged from the previous discussion post. However, this document serves to incorporate Reviewer 3's comments, and com- 
pile all discussion points into one document.

Thank you.

Please also note the supplement to this comment:

https://hess.copernicus.org/preprints/hess-2020-169/hess-2020-169-SC3-

supplement.pdf

Interactive comment on Hydrol. Earth Syst. Sci. Discuss., https://doi.org/10.5194/hess-2020169, 2020. 